\title{
Studies on the Adsorption of p-Aminoazobenzene onto Kaolinite
}

\author{
Qingfeng $\mathrm{Wu}^{1,2}$, Hanlie Hong ${ }^{*}, 1$ and Xiaoling Zhang ${ }^{1}$ \\ ${ }^{1}$ Faculty of Earth Sciences, China University of Geosciences, Wuhan, Hubei 430074, China \\ ${ }^{2}$ College of Physical Science and Technology, Yangtze University, Jingzhou, Hubei, 434100, China
}

\begin{abstract}
As one of the most important soil components, kaolinite plays an important role in transport and fixation of organic pollutants in soils. P-Aminoazobenzene (PAAB) is a sort of the carcinogenic aromatic amine which is commonly used as the intermediates of azo dyes. It can cause mutations and cancer of aquatic biota as well as humans. In this study, adsorption of $\mathrm{PAAB}$ on kaolinite in aqueous solution under different $\mathrm{pHs}$, temperature and ionic strength was examined. Adsorption kinetic experiments indicated that the adsorption of PAAB on kaolinite at $\mathrm{pH} 1.4$ and 4.0 followed the Elovich kinetics. The adsorption isotherm of PAAB onto kaolinite was well described by the Langmuir model, with an adsorption capacity of $2.2 \mathrm{mg} / \mathrm{g}$ at $\mathrm{pH} 1.4$ and $1.43 \mathrm{mg} / \mathrm{g}$ at $\mathrm{pH} 4.0$. Adsorption of PAAB increased with decreasing solution $\mathrm{pH}$ and ionic strength. The negative free energy change $(\Delta \mathrm{G})$ after adsorption indicated that the adsorption process is a spontaneous process. The enthalpy change $(\Delta \mathrm{H})$ at $\mathrm{pH} 1.4$ and 4.0 was -6.93 and $-4.72 \mathrm{~kJ} / \mathrm{mol}$, respectively, suggesting that $\mathrm{PAAB}$ adsorption was an exothermal process and the physical adsorption predominated in the adsorption of $\mathrm{PAAB}$ on kaolinite. The adsorption affinity of PAAB for kaolinite surface was attributed to the electrostatic attractive and van der Waals' forces.
\end{abstract}

Keywords: Adsorption, p-Aminoazobenzene, kaolinite.

\section{INTRODUCTION}

Azo dyes have been widely used in the printing and dyeing for textile, leather, and paper, etc. Due to incomplete utilization, up to $40 \%$ of dyes used during the dyeing process are discharged into municipal effluents. However, current wastewater treatment technology cannot remove dyes in the wastewater completely [1]. As a result, a large amount of dyes will pass through the wastewater treatment plants and enter the environment via different pathways. Although not strongly hazardous, the presence of dyes in the environment will lead to the increasing possibility of the occurrence of cancer [2]. P-Aminoazobenzene (PAAB) is a sort of the carcinogenic aromatic amine which is commonly used as the intermediates of azo dyes. And it has been recommended as an unsafe substance because it may cause cancer to people [3].

Clay minerals are important constituents of soils and sediments, which have large specific surface area and high cation exchange capacity (CEC). Organic compounds in soils tend to be taken up by clay minerals. Therefore, the clay minerals in soils may play an important role in controlling the transport of organic compounds in the environment. In addition, it is a fact that various clay minerals have been used to remove heavy metals and organic pollutants from aqueous solutions [4]. Therefore, it is necessary for us to carry out detailed investigation of the binding affinity of PAAB to the clay minerals. Investigations on sorptive removal of azo dyes employing the raw mineral materials were mainly focused on basic dyes. Basic dyes

\footnotetext{
*Address correspondence to this author at the Faculty of Earth Sciences, China University of Geosciences, Wuhan, Hubei 430074, China; Tel: 86-2767884250; E-mail: hongh18311@yahoo.com.cn
}

often exist in cationic form, while clay minerals are negatively charged [5-9]. Thus, the electrostatic attraction would increase the removal of basic dyes. On the other hand, acidic dyes could be removed by surfactant-modified clay minerals, as they are often in cationic form while surfactantmodified clay minerals surfaces are negatively charged [1011].

Kaolinite is found as a common constituent of soils and sediments. In this work, we investigated the adsorption of $\mathrm{PAAB}$ on kaolinite as a function of PAAB concentration, $\mathrm{pH}$, temperature and cation strength, and then discussed the mechanisms of PAAB adsorption onto kaolinite, which will provide a better understanding of the fate of PAAB in water and soil and guidance for wastewater remediation.

\section{EXPERIMENTAL}

\subsection{Materials}

The kaolinite used in this study was purchased from Maoming, Guangdong, China. XRD and FTIR analysis showed the purity of kaolinite was very high, only containing trace amount of feldspar. The mean particle size measured was $1.4 \mu \mathrm{m}$. The specific surface area (SSA) was $28-30 \mathrm{~m}^{2} / \mathrm{g}$, and the cation exchange capacity (CEC) was $3.6-3.8 \mathrm{cmol} / \mathrm{kg}$ determined by a spot methylene blue method [12].

The p-Aminoazobenzene (PAAB) was obtained from Sinopharm Chemical Reagent Co. Ltd. (Shanghai, China). Its chemical formula is $\mathrm{C}_{12} \mathrm{H}_{11} \mathrm{~N}_{3}$ and structure is presented in Fig. (1). The dissociation constant $(\mathrm{pKa})$ of PAAB is about 2.8. When solution $\mathrm{pH}$ is below pKa, PAAB exists mainly as cationic form $\mathrm{PAAB}^{+}$; while solution $\mathrm{pH}$ is above $\mathrm{pKa}$, the neutral form $\mathrm{PAAB}^{0}$ predominates. All other 
chemicals were of analytical grade. Deionized water was used for all the experiments.

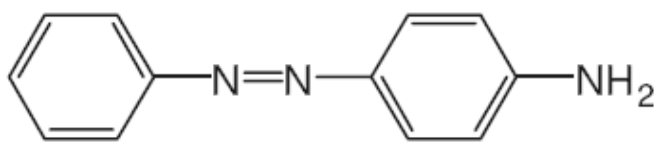

Fig. (1). Molecular structure of p-Aminoazobenzene.

\subsection{Batch adsorption}

Adsorption of PAAB on kaolinite was performed by adding a certain amount of kaolinite and $50 \mathrm{ml}$ of PAAB solution to a $100 \mathrm{ml}$ centrifuge tube. And then, the centrifuge tubes were continuously shaken a reciprocal shaker at 150 rpm for $24 \mathrm{~h}$. Due to the low solubility of PAAB, it was first dissolved in ethanol, and made a $200 \mathrm{mg} / \mathrm{L}$ stock solution that was diluted with deionized water and methanol to desired concentrations. The centrifuge tubes were wrapped with aluminum foils to prevent exposure to light. After equilibration, the mixture was centrifuged at $4200 \mathrm{rpm}$ for 10 min and the supernatant was passed through a $0.45 \mu \mathrm{m}$ filter. The equilibrium concentration of PAAB in the supernatant was determined via $\mathrm{UV}$-vis spectrophotometer. In order to investigate the contribution of different species of PAAB to adsorption, we choose $\mathrm{pH}=1.4$ and 4.0 as the experiment condition, respectively. Although these $\mathrm{pH}$ conditions are rare in natural environments, PAAB adsorption conducted under these $\mathrm{pH}$ conditions could help elucidate the mechanism of PAAB adsorption on kaolinite. Solution $\mathrm{pH}$ was adjusted by adding $0.1 \mathrm{M} \mathrm{NaOH}$ and $\mathrm{HCl}$ using $100 \mu \mathrm{L}$ syringe.

\subsection{Methods of Analysis}

The UV-Vis scan $(200-900 \mathrm{~nm})$ showed that the wavelengths corresponding to maximum absorbance of PAAB at pH 1.4 and 4.0 were 400 and $312 \mathrm{~nm}$, respectively. In order to ensure the accurate measurement of PAAB concentrations, the PAAB concentration was measured by a UV-vis spectrophotometer at the wavelength of $400 \mathrm{~nm}$ at

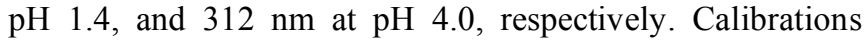
with six initial concentrations ranging from 10 to $50 \mathrm{mg} / \mathrm{L}$ at $\mathrm{pH} 1.4$ and 4.0 resulted in a coefficient of determination $\mathrm{r}^{2}$ $>0.99$.

Powder XRD analyses were carried out on X'Pert PRO Dy 2198 with $\mathrm{Cu}-\mathrm{K} \alpha$ radiation at $40 \mathrm{kV}$ and $30 \mathrm{~mA}$. Oriented samples were scanned from $3^{\circ}$ to $65^{\circ}$ with a scanning speed of $2 \% \mathrm{~min}$.

FTIR spectra were obtained on a Nicolet 60 SXB Fourier transform infrared spectrometer using $\mathrm{KBr}$ pressing method. The absorbance data were collected by accumulating 256 scans at a resolution $4 \mathrm{~cm}^{-1}$ in the range of $4000-400 \mathrm{~cm}^{-1}$.

\section{RESULT AND DISCUSSION}

\subsection{PAAB Adsorption Kinetics}

Kinetics of PAAB adsorption onto kaolinite is shown in Fig. (2). The data were fitted to both pseudo-second-order and Elovich models. The integrated rate law of the pseudosecond-order kinetics model is:

$$
q_{t}=\frac{k q_{e}^{2} t}{1+k q_{e} t}
$$

where $\mathrm{k}(\mathrm{g} / \mathrm{mg}-\mathrm{h})$ is the rate constant of adsorption, $\mathrm{q}_{\mathrm{e}}(\mathrm{mg} / \mathrm{g})$ is the amount of PAAB adsorbed at equilibrium, and $\mathrm{q}_{\mathrm{t}}$ $(\mathrm{mg} / \mathrm{g})$ is the amount of PAAB adsorbed on the surface of the adsorbent at any time $t$. The above equation can be converted into a linear form:

$$
\frac{t}{q_{t}}=\frac{1}{k q_{e}^{2}}+\frac{1}{q_{e}} t
$$

where $\mathrm{kq}_{\mathrm{e}}{ }^{2}$ is the initial rate $(\mathrm{mg} / \mathrm{g}-\mathrm{h})$. When the kinetic data at $\mathrm{pH} 1.4$ were fitted to Eq. (2), the $\mathrm{r}^{2}$ was 0.92 . The initial rate was $0.85 \mathrm{~g} / \mathrm{mg}-\mathrm{h}$, the rate constant was $0.77 \mathrm{~g} / \mathrm{mg}-\mathrm{h}$, and the $\mathrm{q}_{\mathrm{e}}$ was $1.05 \mathrm{mg} / \mathrm{g}$. Fitting of the kinetic data at $\mathrm{pH} 4.0$ to Eq. (2) yielded a coefficient of determination $r^{2}$ of 0.94 . The initial rate was $0.53 \mathrm{~g} / \mathrm{mg}-\mathrm{h}$, the rate constant was $0.96 \mathrm{~g} / \mathrm{mg}$ $\mathrm{h}$, and the $\mathrm{q}_{\mathrm{e}}$ was $0.74 \mathrm{mg} / \mathrm{g}$. Compared to azobenzene adsorption on kaolinite, adsorption of PAAB on kaolinite achieved a lower initial rate and equilibrium adsorption capacity, but a much larger rate constant [13]. The Elovich model can be written as:

$q_{t}=a \ln (t)+b$

where $\mathrm{a}$ and $\mathrm{b}$ are constants. At $\mathrm{pH} 1.4$, the fitted values for a and $\mathrm{b}$ are $0.18 \mathrm{mg} / \mathrm{g}-\mathrm{h}$ and $0.49 \mathrm{mg} / \mathrm{g}$ respectively, with an $\mathrm{r}^{2}$ 0.96 . When solution $\mathrm{pH}$ increased to 4.0 , the two fitted parameters are $0.14 \mathrm{mg} / \mathrm{g}-\mathrm{h}$ and $0.32 \mathrm{mg} / \mathrm{g}$, respectively, with an $r^{2}$ 0.97. Compared to the pseudo-second-order kinetic model, the Elovich model describes the PAAB adsorption better.

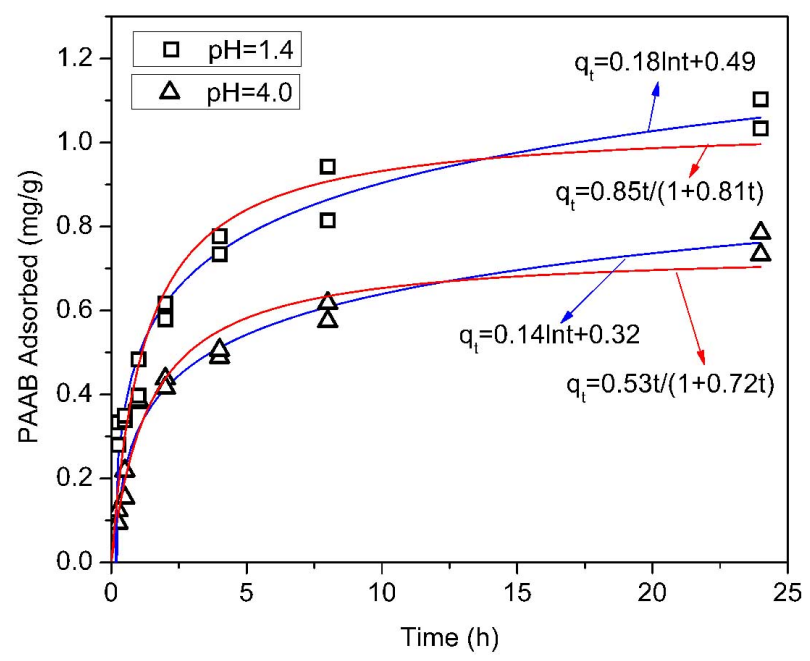

Fig. (2). Kinetics of PAAB adsorption on kaolinite at $\mathrm{pH} 1.4$ and 4.0 fitted to pseudo-second-order (red lines) and Elovich models (blue lines).

\subsection{PAAB Adsorption Isotherm}

The adsorption of PAAB on kaolinite at $\mathrm{pH} 1.4$ and 4.0 was fitted to the Freundlich and Langmuir isotherms. The Freundlich isotherm is expressed as:

$C_{s}=K_{F} C_{L}^{n}$

which can be converted into a linear form

$\log C_{s}=n \log C_{L}+\log K_{F}$

where $\mathrm{C}_{\mathrm{S}}$ is the amount of PAAB adsorbed on kaolinite at equilibrium $(\mathrm{mmol} / \mathrm{g}), \mathrm{C}_{\mathrm{L}}$ is the equilibrium PAAB 
concentration $(\mathrm{mg} / \mathrm{g}), \mathrm{K}_{\mathrm{F}}$ is the Freundlich distribution coefficient, and $\mathrm{n}$ is the linear coefficient. The Freundlich isotherm describes the relationship between equilibrium liquid and solid phase capacity based on the multilayer adsorption. On the contrary, the Langmuir isotherm was assumed with a uniform surface on the adsorbent and all the adsorption sites were equivalent and adsorbed molecules did not interact with each other, resulting in a monolayer adsorption. The Langmuir isotherm has the form of

$$
C_{s}=\frac{K_{L} S_{m} C_{L}}{1+K_{L} C_{L}}
$$

where $S_{m}$ is the adsorption capacity $(\mathrm{mg} / \mathrm{g})$, and $\mathrm{K}_{\mathrm{L}}$ is the Langmuir coefficient (L/mg). Eq. (6) can be converted into a linear form

$\frac{C_{L}}{C_{s}}=\frac{1}{K_{L} S_{m}}+\frac{C_{L}}{S_{m}}$

So that $\mathrm{K}_{\mathrm{L}}$ and $\mathrm{S}_{\mathrm{m}}$ can be determined by a linear regression.

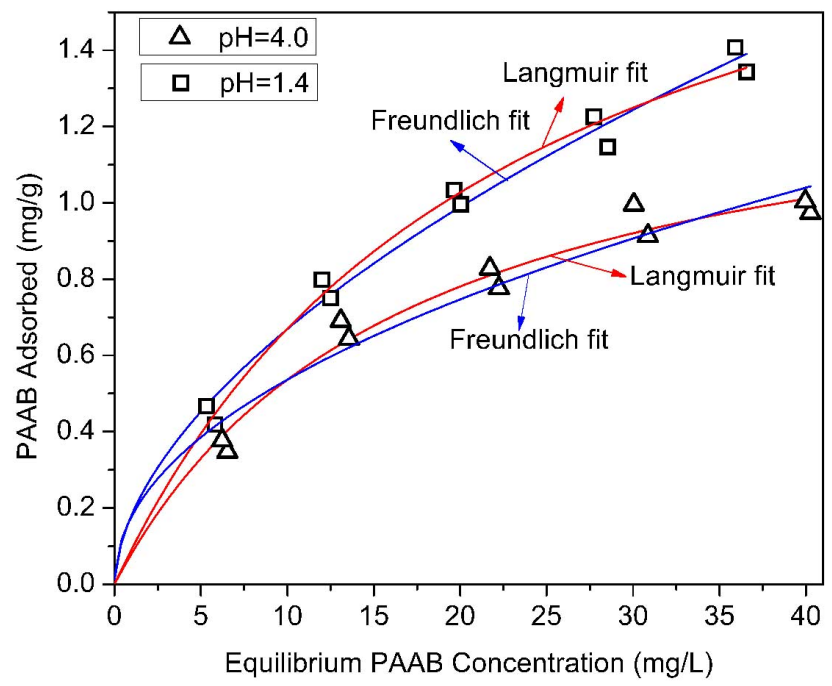

Fig. (3). Adsorption of PAAB on kaolinite at $\mathrm{pH} 1.4$ and 4.0 fitted to Langmuir and Freundlich isotherms.

As shown in Fig. (3), Langmuir isotherm fitted the experimental data better than Freundlich isotherm, indicating a surface-limited or charge-limited adsorption rather than a multilayer adsorption. At $\mathrm{pH} 1.4$, the fitted $\mathrm{K}_{\mathrm{L}}$ and $\mathrm{S}_{\mathrm{m}}$ values were $0.044 \mathrm{~L} / \mathrm{mg}$ and $2.2 \mathrm{mg} / \mathrm{g}$, respectively, comparable to $0.06 \mathrm{~L} / \mathrm{mg}$ and $1.43 \mathrm{mg} / \mathrm{g}$ at $\mathrm{pH}$ 4.0. The fitted $\mathrm{K}_{\mathrm{F}}$ and $\mathrm{n}$ values were 0.18 and $0.56 \mathrm{~L} / \mathrm{g}$, respectively, compared to 0.18 and $0.48 \mathrm{~L} / \mathrm{g}$ at $\mathrm{pH} 4.0$. The larger adsorption capacity $\mathrm{S}_{\mathrm{m}}$ at $\mathrm{pH} 1.4$ than at $\mathrm{pH} 4.0$ indicated that PAAB had higher affinity for kaolinite in more acidic conditions.

As indicated by the higher regression coefficient, Langmuir isotherm was found better describing adsorption of PAAB on kaolinite than Freundlich isotherm. On the contrary, a study of the adsorption of Azo Dye C.I. Acid Red 14 on surface soils indicated that Freundlich isotherm fitted the data better than Langmuir isotherm [9]. However, the adsorption of methylene blue on raw, calcined and $\mathrm{NaOH}-$ treated kaolinite could be fitted well by both Freundlich and Langmuir equations [14]. The adsorption capacity of PAAB on kaolinite in this study is lower than that of azobenzene on kaolinite [13].

\subsection{Effect of Temperature on $\mathrm{PAAB}$ Adsorption}

The temperature effect on PAAB distribution between the solid and the liquid phase is expressed by

$\log K_{d}=-\frac{\Delta H}{2.303 R T}+\frac{\Delta S}{R}$

where $\mathrm{K}_{\mathrm{d}}$ is the distribution coefficient of PAAB between the solid and liquid phases, $\Delta \mathrm{H}$ is the change in enthalpy, $\Delta \mathrm{S}$ is the change in entropy, $\mathrm{R}$ is the gas constant $\left(8.31 \mathrm{Jmol}^{-1} \mathrm{~K}^{-1}\right)$, and $\mathrm{T}$ is the operated temperature $(\mathrm{K})$. When $\log \mathrm{K}_{\mathrm{d}}$ is plotted versus $1 / \mathrm{T}$, a straight line is obtained (Fig. 4). The values of $\Delta \mathrm{H}$ and $\Delta \mathrm{S}$ estimated from the slope and intercept are -6.93 $\mathrm{kJ} / \mathrm{mol}$ and $-8.73 \mathrm{~J} / \mathrm{mol} \cdot \mathrm{K}$ at $\mathrm{pH} 1.4$, respectively, compared to $-4.72 \mathrm{~kJ} / \mathrm{mol}$ and $-6.15 \mathrm{~J} / \mathrm{mol} \cdot \mathrm{K}$ at $\mathrm{pH} 4.0$. The linear regressions were performed with Origin 8.0. When $\mathrm{pH}$ is 1.4, the standard errors of $\Delta \mathrm{H}$ and $\Delta \mathrm{S}$ estimated from the fitting results are 0.84 and 1.2 , respectively. While $\mathrm{pH}$ is 4.0 , the standard errors of $\Delta \mathrm{H}$ and $\Delta \mathrm{S}$ decrease to 0.39 and 0.56 , respectively.

$\Delta G=\Delta H-T \Delta S$

The change in free energy $\Delta \mathrm{G}$ after PAAB adsorption at $\mathrm{pH} 1.4$ and 4.0 calculated based on equation (9) is -4.33 $\mathrm{kJ} / \mathrm{mol}$ and $-2.89 \mathrm{~kJ} / \mathrm{mol}\left(\right.$ at $25{ }^{\circ} \mathrm{C}$ ), respectively. The negative $\Delta \mathrm{G}$ value indicated the adsorption of PAAB on kaolinite was a spontaneous process. The $\Delta \mathrm{G}$ value from this study is less negative compared to those for methylene blue adsorption on kaolinite. The negative $\Delta H$ value suggested that PAAB adsorption was an exothermal process and therefore decrease in temperature should facilitate the adsorption of PAAB onto kaolinite. The $\Delta \mathrm{H}$ could be used to make a distinction between physical and chemical adsorption with a borderline at $-40 \mathrm{~kJ} / \mathrm{mol}$. The $\Delta \mathrm{H}$ value of -6.93 and $4.72 \mathrm{~kJ} / \mathrm{mol}$ suggested that the physical adsorption was the main interaction mechanism. The electrostatic attraction and van der Waals' force played an important role in the adsorption of PAAB on kaolinite.

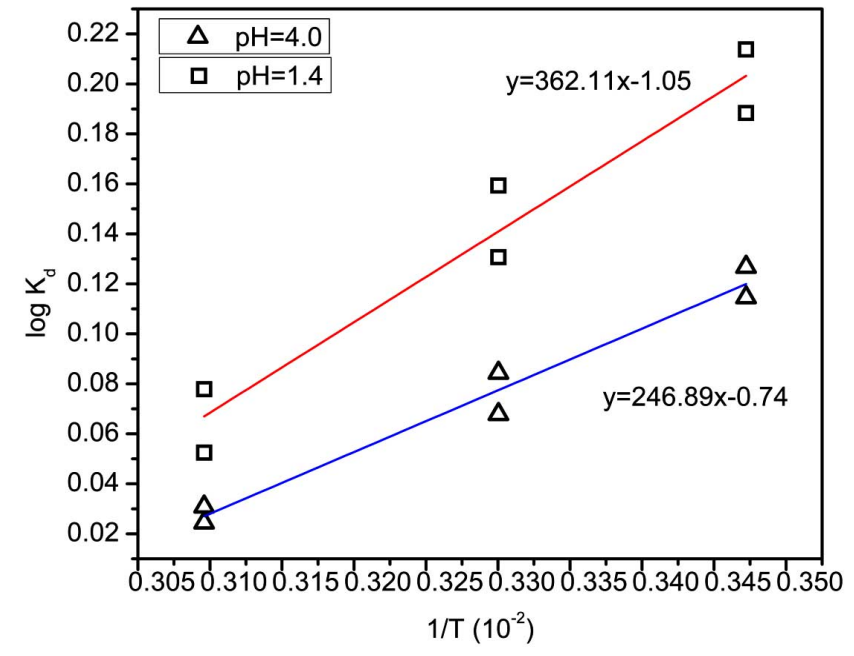

Fig. (4). Linear relation between $\log \mathrm{K}_{\mathrm{d}}$ and $1 / \mathrm{T}$. 


\subsection{Effect of Ionic Strength on PAAB Adsorption}

In general, there is a certain concentration of inorganic salt in natural environment. Thus, it is essential to investigate the effect of inorganic cations on the adsorption of PAAB on kaolinite. As illustrated in Fig. (5), a decrease in PAAB adsorption is accompanied by an increase in ionic strength. In acidic condition, PAAB molecules exist in a cationic form due to the protonation of the amine group, and the adsorption of PAAB on kaolinite was mainly via cation exchange. With the increasing $\mathrm{Na}^{+}$concentration, the increasing competition between $\mathrm{Na}^{+}$and the cationic form PAAB for adsorption sites results in lower adsorption of PAAB.

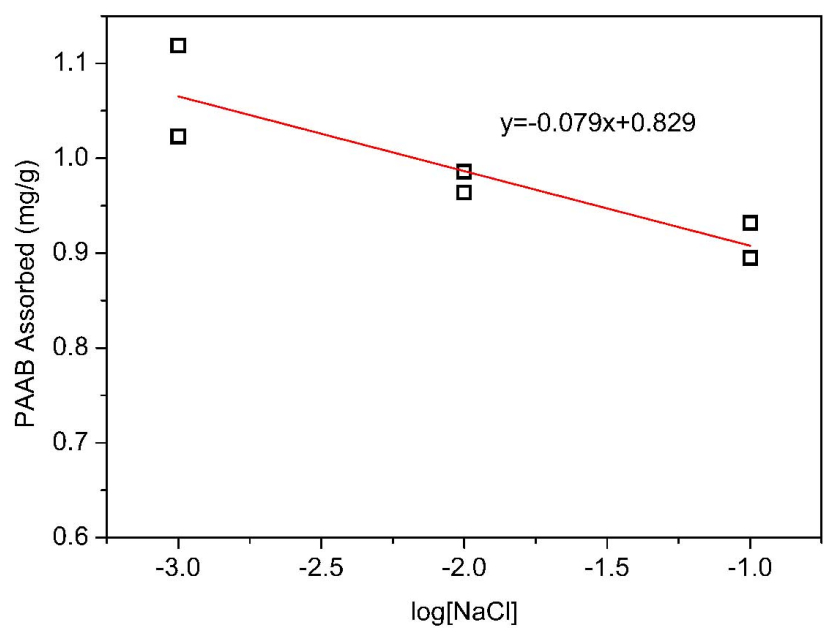

Fig. (5). Influence of ionic strength on PAAB adsorption.

\subsection{XRD Analysis}

The XRD analysis indicated that no change in the $\mathrm{d}_{001^{-}}$ spacing of kaolinite was observed after equilibrium with PAAB for $24 \mathrm{~h}$, suggesting that the adsorption takes place mainly on the external surface of kaolinite (Fig. 6). Comparatively, the adsorption benzaminde, nitroaniline and cyclic imides on kaolinite resulted in the expansion of interlayer space [15-17].

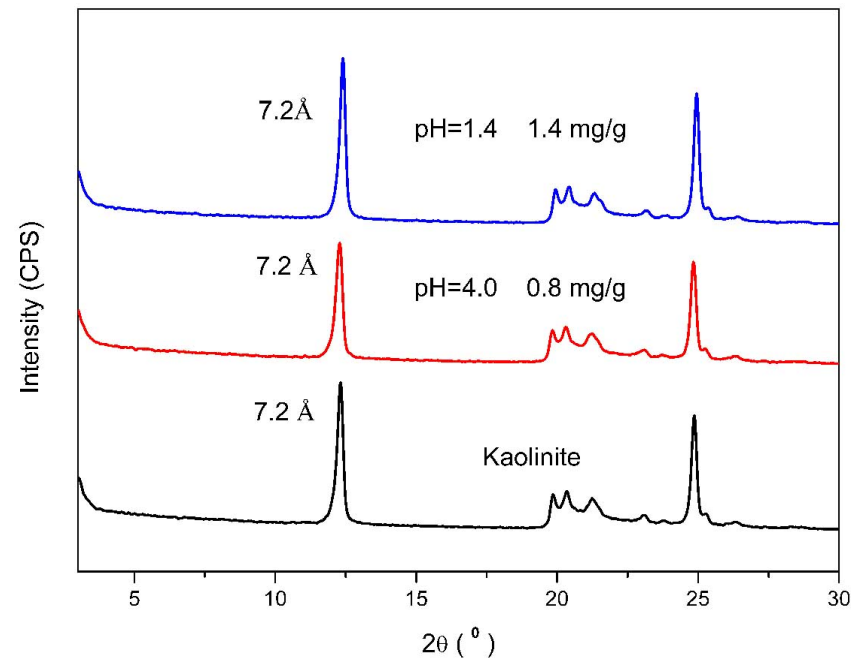

Fig. (6). XRD patterns of kaolinite and PAAB-loaded kaolinite.

\subsection{FTIR Analysis}

The FTIR spectra of PAAB, mixture of PAAB and kaolinite and PAAB-loaded kaolinite are shown in Fig. (7). As indicated in Fig. (7), the characteristic spectrum of PAAB did not appear in the spectra of mixture of PAAB and kaolinite, which may be attributed to the fact that the amount of PAAB in mixture is too small. The absorption bands at 3694 and $3623 \mathrm{~cm}^{-1}$ are ascribed to the stretching vibration of the surface hydroxyl. The peaks at 1105 and $1026 \mathrm{~cm}^{-1}$ are due to stretching vibration from Si-O, while the peak at 918 $\mathrm{cm}^{-1}$ is assigned to the deformation vibration of Al-O-H [18]. Compared with the spectra of mixture of PAAB and kaolinite, new bands at $1515 \mathrm{~cm}^{-1}$ were observed in the spectra of the PAAB-loaded kaolinite, which originated from the PAAB adsorbed on the surface of kaolinite $[19,20]$. As shown in Fig. (7), the main band position for Si-O, Al-O-H and $\mathrm{PAAB}$ show no apparent shift, indicating that the adsorption of PAAB on kaolinite surface was attributed to the electrostatic attraction and van der Waals' force between the surface and PAAB molecules.

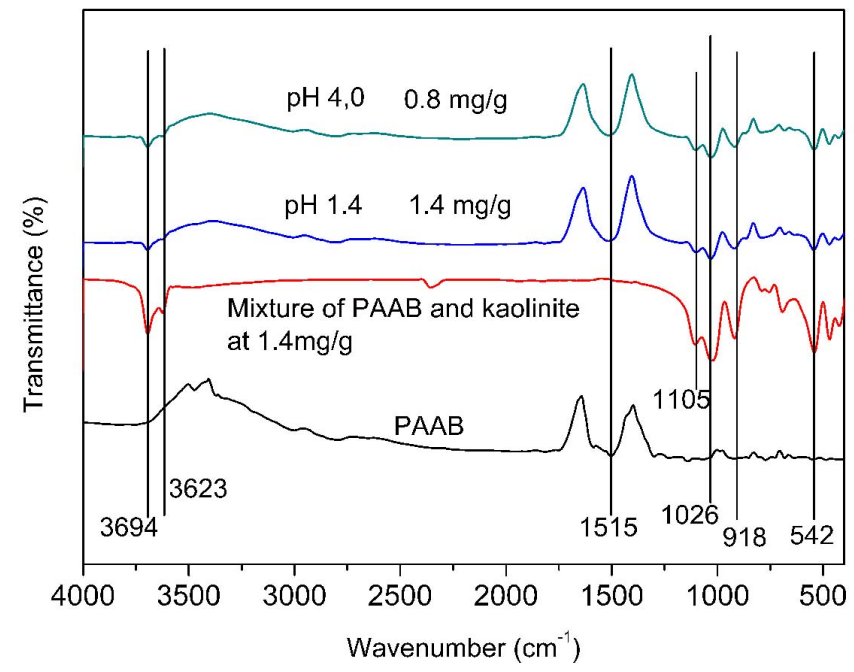

Fig. (7). FTIR spectra of mixture of PAAB and kaolinite and PAAB-loaded kaolinite.

\section{CONCLUSION}

The adsorption of PAAB on kaolinite was systematically studied under different conditions. The adsorption of PAAB was found to increase with decreasing $\mathrm{pH}$ and ionic strength. The change in free energy $\Delta \mathrm{G}$ after PAAB adsorption at $\mathrm{pH}$ 1.4 and 4.0 is -4.33 and $-2.89 \mathrm{~kJ} / \mathrm{mol}$, respectively. The negative $\Delta \mathrm{G}$ value indicated that the adsorption of PAAB on kaolinite is a spontaneous and favorable process. The enthalpy change $(\Delta \mathrm{H})$ at $\mathrm{pH} 1.4$ is $-6.93 \mathrm{~kJ} / \mathrm{mol}$, compared to $-8.73 \mathrm{~kJ} / \mathrm{mol}$ at $\mathrm{pH} 4.0$, suggesting that the interaction between the adsorbent and the adsorbate molecules was physical rather than chemical. X-ray diffraction and FTIR spectroscopy exhibit no significant change in XRD pattern and FTIR spectra, indicating the adsorption of PAAB on kaolinite was mainly attributed to the electrostatic attraction and van der Waals' force between the surface of kaolinite and the PAAB molecules. 


\section{ACKNOWLEDGEMENTS}

The study is supported by the Key Project of Chinese Ministry of Education (10706) and the Technology Creative Project of Excellent Middle \&Young Team of Hubei Province (T201204).

\section{CONFLICT OF INTEREST}

Declared none.

\section{REFERENCES}

[1] Correia VM, Stephenson T, Judd SJ. Characteristics of textile wastewater-a review. Environ Technol 1994; 15: 917-29.

[2] McKay G, Otterburn MS, Aga D. A. Fullers earth and fired clay as adsorbent for dye stuffs. Equilibrium and rate constants. Water Air Soil Pollut 1985; 24: 307-22.

[3] Zhang YZ, Zhou B, Liu YX, Zhou CX, Ding XL, Liu Y. Fluorescence study on the interaction of bovine serum albumin with p-aminoazobenzene. J Fluoresc 2008; 18: 109-18.

[4] Lagaly G. Bentonites: adsorbents of toxic substances. Prog Colloid Polym Sci 1994; 95: 61-72.

[5] Liu RX, Liu XM, Tang HG, Su Y. Sorption behavior of dye compounds onto natural sediment of Qinghe River. J Colloid Interface Sci 2001; 239: 475-82.

[6] Gupta VK, Ali I, Suhas, MD. Equilibrium uptake and sorption dynamics for the removal of a basic dye (basic red) using low cost adsorbents. J Colloid Interface Sci 2003; 265: 257-64.

[7] Gupta VK, Mohan D, Saini VK. Studies on the interaction of some azo dyes (naphthol red-J and direct orange) with nontronite mineral. J Colloid Interface Sci 2006; 298: 79-86.

[8] Jain AK, Gupta VK, Bhatnagar AS. Utilization of industrial waste products as adsorbents for the removal of dyes. J Hazard Mater 2003; 101: 31-42.
[9] Qu BC, Zhou JT, Xiang XM, Zheng CL, Zhao HX, Zhou XB. Adsorption behavior of Azo Dye C.I. Acid Red 14 in aqueous solution on surface soils. J Environ Sci 2008; 20: 704-9.

[10] Benkli YE, Can MF, Turan M, Celik MS. Modification of organozeolite surface for the removal of reactive azo dyes in fixed-bed reactors. Water Res 2005; 39: 487-93.

[11] Wang L, Wang A. Adsorption properties of Congo Red from aqueous solution onto surfactant-modified montmorillonite. J Hazard Mater 2008; 160: 173-80.

[12] Yukselen Y, Kaya A. Suitability of the methylene blue test for surface area, cation exchange capacity and swell potential determination of clayey soils. Eng Geol 2008; 102: 38-45.

[13] Zhang XL, Hong HL, Li ZH, Guan JF, Schulz L. Removal of azobenzene from water by kaolinite. J Hazard Mater 2009; 170: 1064-9.

[14] Ghosh D, Bhattacharyya KG. Adsorption of methylene blue on kaolinite. Appl Clay Sci 2002; 20: 295-300.

[15] Gardolinski JE, Ramos LP, de Souza GP, Wypych F. Intercalation of benzamide into kaolinite. J Colloid Interface Sci 2000; 221: 28490 .

[16] Takenawa R, Komori Y, Hayashi S, Kawamata J, Kuroda K Intercalation of nitroanilines into kaolinite and second harmonic generation. Chem Mater 2003; 13: 3741-6.

[17] Elbok1 TA, Detellier C. Intercalation of cyclic imides in kaolinite. J Colloid Interface Sci 2008; 323: 338-48.

[18] Xu TJ, Wang HJ. An IR spectroscopy study of kaolinite from Jingdezhen area. Acta Petrologica et Mineralogical 2010; 29(1): 59-66.

[19] Armstrong DR, Clarkson J, Smith WE. Vibrational analysis of transazobenzene. J Phys Chem 1995; 99: 17825-31.

[20] Biswas N, Umapathy S. Structures, vibrational frequencies, and normal modes of substituted azo dyes: infrared, Raman, and density functional calculations. J Phys Chem A 2000; 104: 273445 .

(C) Wu et al.; Licensee Bentham Open.

This is an open access article licensed under the terms of the Creative Commons Attribution Non-Commercial License (http: //creativecommons.org/licenses/by$\mathrm{nc} / 3.0 /$ ) which permits unrestricted, non-commercial use, distribution and reproduction in any medium, provided the work is properly cited. 